\title{
Cationic polymer modified PLGA nanoparticles encapsulating Alhagi honey polysaccharides as a vaccine delivery system for ovalbumin to improve immune responses
}

This article was published in the following Dove Press journal:

International Journal of Nanomedicine

\author{
Adelijiang Wusiman ${ }^{1,2}$ \\ Pengfei Gu ${ }^{1,2}$ \\ Zhenguang Liu ${ }^{1,2}$ \\ Shuwen $\mathrm{Xu}{ }^{\mathrm{I}, 2}$ \\ Yue Zhang ${ }^{1,2}$ \\ Yuanliang $\mathrm{Hu}^{1,2}$ \\ Jiaguo Liu ${ }^{1,2}$ \\ Deyun Wang ${ }^{1,2}$ \\ Xiaoyan Huang ${ }^{3}$

\begin{abstract}
'Institute of Traditional Chinese Veterinary Medicine, College of Veterinary Medicine, ${ }^{2} \mathrm{MOE}$ Joint International Research Laboratory of Animal Health and Food Safety, College of Veterinary Medicine, Nanjing Agricultural University, Nanjing 210095 , People's Republic of China; ${ }^{3}$ Experiment Center for Science and Technology, Shanghai University of Traditional Chinese Medicine, Shanghai 201203, People's Republic of China
\end{abstract}

Correspondence: Deyun Wang Institute of Traditional Chinese Veterinary Medicine, College of Veterinary Medicine, Nanjing Agricultural University, Nanjing 210095, People's Republic of China

Tel +862584395203

Fax +862584398669

Email dywang@njau.edu.cn

Xiaoyan Huang

Experiment Center for Science and Technology, Shanghai University of

Traditional Chinese Medicine, Shanghai

201203, People's Republic of China

Tel +86 2II I32 2648

Fax +86 2I5 I32 2740

Email huangxiaoyan821I@I63.com
Background: Poly (lactic-co-glycolic acid) (PLGA) nanoparticles and surface modified PLGA nanoparticles have been widely studied as antigens or drugs carriers due to their controlled release characteristics and biocompatibility. However, most PLGA nanoparticles have lower antigens loading efficiency and adjuvanticity.

Purpose: The aim of this study was to improve the antigen loading efficiency and adjuvant activity of PLGA nanoparticles.

Materials and methods: Surface cationic polymer modification can improve the antigens loading efficiency of PLGA nanoparticles by surface adsorption. Therefore, in this study, chitosan modified PLGA nanoparticles (CS-AHPP/OVA), polyethyleneimine modified PLGA nanoparticles (PEI-AHPP/OVA), and $\varepsilon$-Poly-L-lysine modified PLGA nanoparticles ( $\mathrm{PPL}-\mathrm{AHPP} / \mathrm{OVA}$ ) were prepared as antigen delivery carriers to investigate the characterization and stability of these nanoparticles. These nanoparticles were evaluated for their efficacies as adjuvants pre- and post-modification.

Results: The AHP and OVA-loaded PLGA nanoparticles (AHPP/OVA) were positively charged after surface cationic polymers modification, and their structural integrity was maintained. Their antigen loading capacity and stability of nanoparticles were improved by the surface cationic polymers modification. Increased positive surface charge resulted in greater OVA adsorption capacity. Among AHPP/OVA and the three surface cationic polymers synthesized from modified PLGA nanoparticles, PEI-AHPP/OVA showed the highest antigen loading efficiency and good stability. AHPP/OVA, CS-AHPP/OVA PEI-AHPP/OVA, and $\varepsilon P L-A H P P / O V A$ formulations significantly enhanced lymphocyte proliferation and improved the ratio of $\mathrm{CD} 4+/ \mathrm{CD} 8+\mathrm{T}$ cells. In addition, AHPP/OVA, PEI-AHPP/OVA and $\varepsilon$ PL-AHPP/OVA formulations induced secretion of cytokines (TNF- $\alpha$, IFN- $\gamma$, IL- 4 , and IL6 ), antibodies (IgG) and antibody subtypes (IgG1 and $\operatorname{IgG} 2 \mathrm{a}$ ) in immunized mice. These results demonstrate that these formulations generated a strong Th1-biased immune response. Among them, PEI-AHPP/OVA induced the strongest Th1-biased immune response.

Conclusion: In conclusion, PEI-AHPP/OVA nanoparticles may be a potential antigen delivery system for the induction of strong immune responses.

Keywords: Alhagi honey polysaccharides, cationic polymer, poly(lactic-co-glycolic acid), nanoparticles, OVA

\section{Introduction}

Particulate antigen delivery systems eg, poly (lactic-co-glycolic acid) (PLGA), PLA, chitosan (CS), and liposomes etc.-based nanoparticle or microspheres are 
developed as the new adjuvants, to stimulate immune responses and defend against various infectious diseases. $^{1,2}$ Among the biomaterials-based nanoparticle drug delivery system, PLGA nanoparticles are the most promising material which shows great potential to be used as a carrier in drug delivery and as scaffolds in tissue engineering. Favorable characteristics of PLGA include safety, biodegradability, and stability and so on. ${ }^{3,4}$ PLGA can be used as a drug carrier in combination with organic materials and inorganic materials. PLGA nanoparticles combined with $\mathrm{Fe}_{3} \mathrm{O}_{4}$ or $\mathrm{NH}_{4} \mathrm{HCO}_{3}$ may serve as a "smart" nanostructures avenues in disease therapy., 5 The combination of PLGA with polyethylene glycol or polyethylene oxide, can control the flow pattern of nanoparticles to enhance their targeting effect. ${ }^{3,7}$ A number of studies have demonstrated that encapsulation of antigens or polysaccharides into PLGA nanoparticles increased antigen-presenting cell (APC) antigen uptake, controlled drug release, and also enhanced cellular and humoral immune responses. ${ }^{8,9}$ Particulate vaccine delivery systems such as PLGA nanoparticles can induce cross presentation of antigens to elicit both $\mathrm{CD} 4^{+}$and $\mathrm{CD}^{+} \mathrm{T}$ cell responses, resulting in strong antigen-specific immune responses. ${ }^{10,11}$

PLGA nanoparticle adjuvants function through encapsulation of antigens or drugs into nanoparticles. Although PLGA nanoparticles are relatively stable and exhibit high encapsulation efficiency for ovalbumin (OVA) and drugs, washing, and centrifugation during the preparation of nanoparticles can result in decreased in loading efficiency. ${ }^{12,13}$ In addition, encapsulation of large drug amounts also affects the stability of the nanoparticles. Therefore, measures need to be taken to improve loading efficiency of PLGA nanoparticles. Adsorption of antigens on the surface of PLGA nanoparticles is a common loading method and can induce a strong immune response in the body. ${ }^{14,15}$ High antigen loading is promoted through a combination of antigen adsorption and antigen encapsulation. CS, polyethyleneimine (PEI), and $\varepsilon$-Poly -L-lysine ( $(\mathrm{PL})$ are the most widely used cationic polymers for coating. ${ }^{16-18}$ Recent studies have shown that cationic polymers, like CS, PEI, and $\varepsilon$ PL afford facile chemical conjugation to the surfaces of PLGA nanoparticles, while allowing retention of internal microstructure. ${ }^{18-20}$ In addition, positively charged PLGA nanoparticles make more effective contact with APCs and induce a stronger immune response in vivo. 9,21

Multiple pharmacological activities and the strong immunomodulatory effects of polysaccharides support their use as vaccine adjuvants. $^{22,23}$ Alhagi honey is a light yellow granulated sugar condensed from secreted fluid of Alhagi pseudalhagi Desv has been traditionally used as an herbal medicinal material in China. ${ }^{24}$ It is normally used as an immunomodulator to enhance immunity, and as a remedy for cough. ${ }^{25}$ Modern studies have shown that the major constituent of Alhagi honey is polysaccharides, which exert various pharmacological effects such as enhanced immunity, anti-tumor effects, and hepatoprotective effects. ${ }^{24,26}$

To improve the antigen-loading efficiency of PLGA nanoparticles and the intensity of the immunomodulatory effects, three surface cationic polymers synthesized from modified PLGA nanoparticles were prepared. Good antigen encapsulation efficiency and antigen adsorption capacity showed that surface cationic polymer modified PLGA nanoparticles were excellent antigen carriers. In addition, modified PLGA nanoparticles exhibited good sustained release of Alhagi honey polysaccharides (AHP) and stimulated strong cellular immune responses. The aim of this study was to develop new nanoparticle adjuvants, to stimulate humoral and cellular immune responses.

\section{Material and method Materials}

Alhagi honey was purchased from the hospital of Xinjiang traditional Uyghur medicine in Urumqi, China. PLGA (75:25, molecular weight $18 \mathrm{kDa}$ ) was purchased from Jinan Daigang Biomaterial (Shandong, China). Pluronic F68 (F68) was purchased from Shanghai Yuanye Biotechnology (Shanghai, China). \&PL (MW<5,000) was purchased from Shanghai Macklin Biotechnology (Shanghai, China). DEAE-52, Spandex G-100, and MicroBCA Protein Assay Kit were purchased from Solarbio Science \& Technology Co. (Beijing, China). Chitosan-low molecular weight (CS, 75-85\% deacetylated, MW 50-190 $\mathrm{kDa}$ ), PEI (MW $25 \mathrm{kDa})$, 3-(4,5-dimethylthiazol-2-yl)2,5-diphenyltetrazolium bromide (MTT), Freund's complete adjuvant (FCA), and OVA were purchased from SigmaAldrich Co. (Louis, USA). Dimethyl sulfoxide was purchased from Zhengxing Institute of Chemical Engineering (Suzhou, China). Anti-Mouse-CD3e-FITC, anti-Mouse-CD 4-APC, and anti-Mouse-CD8a-FITC antibodies were all purchased from eBioscience Inc. (San Diego, USA). Assay kits for OVA-specific IgG, IgG1, IgG2a, IL-4, IL-6, IFN- $\gamma$, and TNF- $\alpha$ were purchased from Wuhan Boster Biological Technology (Wuhan, China). All other chemicals used were of analytical grade. 


\section{Preparation of AHP and ova-loaded PLGA nanoparticles}

AHP was extracted and purified using a previously described preparative column chromatography method, ${ }^{27}$ AHP [MW 47,479 Da, main chain-2,3)- $\alpha$-L-Rhap- $(1,2,6)$ $\alpha-\mathrm{D}-$ Manp-(1,3)- $\beta-\mathrm{D}-$ Galp- $(1,3,6) \quad \alpha-\mathrm{D}-$ Galp- $(1-$, while the side chain is composed of $\alpha$-D-Glcp-(1-] carbohydrate and protein contents were $99.0 \%$ and $0.7 \%$, respectively. OVA and AHP-loaded PLGA nanoparticles (AHPP/OVA) were prepared using a water/oil/water (w/o/w) double emulsion technique. ${ }^{28}$ Briefly, $125 \mu \mathrm{L}$ of OVA and AHP aqueous solution $\left(\mathrm{w}_{1}, 40 \mathrm{mg} / \mathrm{mL}\right)$ was added to $1.25 \mathrm{~mL}$ of PLGA dichloromethane solution $(\mathrm{o}, 40 \mathrm{mg} / \mathrm{mL})$. The mixture was probe sonicated ( $5 \%$, amplitude) for $90 \mathrm{~s}$ in an ice bath to obtain the primary emulsion $\left(\mathrm{w}_{1} / \mathrm{o}\right)$. The primary emulsion was then mixed with Pluronic F68 (F68) solution ( $\mathrm{w}_{2}, 0.8$ $\mathrm{w} / \mathrm{v})$ for 2 mins $(10 \%$, amplitude) and stirred to evaporate the organic solvent and form a stable AHPP/OVA solution $\left(\mathrm{w}_{1} / \mathrm{o} / \mathrm{w}_{2}\right.$ emulsion). Blank/OVA PLGA nanoparticles (BP/ OVA) were prepared in the same manner, but without AHP.

After obtaining a stable AHPP/OVA solution, CS solution ( $300 \mu \mathrm{L}, 5 \mathrm{mg} / \mathrm{mL}, 0.1 \mathrm{M}$ acetic acid solution), $\varepsilon \mathrm{PL}$ solution ( $300 \mu \mathrm{L}, 5 \mathrm{mg} / \mathrm{mL}$, deionized water solution), and PEI solution ( $400 \mu \mathrm{L}, 5 \mathrm{mg} / \mathrm{mL}$, deionized water solution) were added to $10 \mathrm{~mL}$ of AHPP/OVA solution. The emulsion was mixed with gentle stirring for $3 \mathrm{hrs}$ achieve effective surface coating. Cation-modified nanoparticles were washed three times with deionized water with centrifugation at 12,000 rpm for $30 \mathrm{mins}$ and lyophilized.

\section{Loading efficiency and characterization of nanoparticles}

AHP and OVA-loading efficiency in AHPP/OVA and surface cationic polymer modified nanoparticles were measured using the phenol-sulfuric acid method, and MicroBCA Protein Assay Kit. ${ }^{29}$ Samples were centrifuged at $12,000 \mathrm{rpm}$ for $30 \mathrm{mins}$ at $4^{\circ} \mathrm{C}$, AHP and OVA were measured in the supernatant. Particle size, polydispersity index (PDI) and zeta-potential were measured by laser diffraction using a laser particle size analyzer (Hydro2000Mu, MAL1009117, Malvern Instruments, UK). Each batch was analyzed in triplicate. Morphological examination of the resultant nanoparticles was performed using scanning electron microscopy (Model S-4800 II FESEM, Hitachi, High-Technologies Co., Ltd, Japan).
Release of OVA from nanoparticles was measured by monitoring free OVA changes in solution. Six milliliters of AHPP/OVA and three surface cationic polymers synthesized from polymer modified PLGA nanoparticles $(500 \mathrm{mg} / \mathrm{mL})$ were dispersed in $30 \mathrm{~mL}$ of deionized water $(\mathrm{pH}=7.0)$ and placed in a shaker bath $\left(37^{\circ} \mathrm{C}, 80 \mathrm{rpm}\right)$. At predetermined intervals $(2,4,6,8,12$ hrs and 1, 2, 4, 8, 12, 16, 20, 24, 30, 35 days), the suspensions were centrifuged at $12,000 \mathrm{rpm}$ for 30 mins. Free OVA in supernatants was determined by the Micro-BCA Protein Assay Kit, and each batch was analyzed in triplicate.

Nanoparticle dispersions were performed in tubes and stored at $37^{\circ} \mathrm{C}$. Physical stability was assessed by monitoring changes in PDI and aggregation. Each sample measurement was performed in triplicate.

\section{Animal immunization}

ICR mice (7 weeks old) were obtained from Comparative Medicine Centre of Yangzhou University. Mice were specific pathogen-free, and all animal experiments were performed in compliance with the guide for the care and use of laboratory animals, Nanjing Agricultural University IACUC, and the protocol was approved by the IACUC (No.: 2011BAD34B02).

Mice were inoculated subcutaneously $(50 \mu \mathrm{g}$ OVA per mouse) with the following nine formulations: AHP/OVA (50 $\mu \mathrm{g}$ AHP in $200 \mu \mathrm{L}$ and OVA), AHPP/OVA (50 $\mu \mathrm{g}$ AHPP in $200 \mu \mathrm{L}$ and OVA), CS-AHPP/OVA (50 $\mu \mathrm{g}$ CS-AHPP in 200 $\mu \mathrm{L}$ and OVA), PEI-AHPP/OVA (50 $\mu$ g PEI-AHPP in $200 \mu \mathrm{L}$ and OVA), $\varepsilon$ PL-AHPP/OVA (50 $\mu \mathrm{g} \varepsilon \mathrm{PL}-\mathrm{AHPP}$ in $200 \mu \mathrm{L}$ and OVA), and BP/OVA (50 $\mu \mathrm{g}$ OVA $+50 \mu \mathrm{g}$ BP in $200 \mu \mathrm{L}$ and OVA). PBS, OVA, and FCA/OVA (FCA emulsified with OVA) were used as controls. Mice were vaccinated subcutaneously with the nine groups of formulations, and boosted with equivalent doses at day 14 after initial immunization. Mice were sacrificed at days 7, 21, and 35 after the second immunization, and blood and spleens were collected. Serum samples were separated and stored at $-80^{\circ} \mathrm{C}$.

\section{Splenocyte proliferation assay}

Splenic lymphocytes were isolated from immunized mice on day 21 after the second immunization. Splenocytes $\left(2.5 \times 10^{5}\right.$ cells $\left./ \mathrm{mL}\right)$ were re-suspended in complete medium and re-stimulated with OVA $(50 \mu \mathrm{g} / \mathrm{mL})$, then incubated for $48 \mathrm{hrs}$. Cells in the blank cells group were used as controls. MTT assay was used to assess cell proliferation. Proliferation index $=\left(\mathrm{A}_{570}\right.$ (experimental group $) / \mathrm{A}_{570}$ 
(control group). ${ }^{19}$ Each test consisted of four repeated measurements.

\section{Lymphocyte immunophenotype analysis}

To investigate the $\mathrm{T}$ lymphocyte subpopulation, splenic lymphocytes were harvested from immunized mice on day 21 after the second immunization. Splenocytes $\left(1 \times 10^{6}\right.$ cells $\left./ \mathrm{mL}\right)$ were seeded on a 24 -well plate, restimulated with OVA $(50 \mu \mathrm{g} / \mathrm{mL})$, and incubated for 60 hrs. Cells were collected and stained with anti-CD3eFITC, anti-CD4-APC, and anti-CD8a-PE antibodies (eBioscience, USA) for 30 mins at $4{ }^{\circ} \mathrm{C}$ in the dark. Cells were washed twice with PBS, resuspended in $0.5 \mathrm{~mL}$ PBS, then analyzed by flow cytometry (FACSCalibur, BD Biosciences, San Jose, CA, USA). Experiments were conducted in quadruplicate.

\section{Determination of antibodies and cytokine levels}

OVA-specific IgG1 and IgG2a isotypes and IL-6, IL-4, IFN- $\gamma$, and TNF- $\alpha$ levels in serum were analyzed on day 35 after the second immunization by enzyme-linked immunosorbent assay (ELISA), OVA-specific IgG antibody levels were analyzed on days 7, 21, and 35 by ELISA.

\section{Statistical analysis}

Quantitative data were expressed as means \pm SEM. Statistical significance was analyzed using Duncan's multiple range test. A probability value $(P)$ less than 0.05 was considered statistically significant.

\section{Results}

\section{Characterization of nanoparticles}

AHPP/OVA was prepared using a modified solvent emulsification-evaporation method. Surface-modified AHPP/OVA was prepared (Figure 1A), and free OVA in solution was adsorbed on to surface of the cationic polymer modified nanoparticles. As shown in Figure 1B, the loading efficiency of AHP in AHPP/OVA, PEI-AHPP/OVA, and $\varepsilon P L-A H P P / O V A$ was about $60 \%$, while loading in the CS-AHPP/OVA group was decreased to about 55\%. Loading efficiency of OVA in AHPP/ OVA was 58\%. Loading efficiencies of OVA in CS-AHPP /OVA, PEI-AHPP/OVA, and \&PL-AHPP/OVA were $(72 \%$, $78 \%$, and $76 \%$, respectively) due to OVA adsorption to nanoparticle surfaces. As shown in Figure $1 \mathrm{C}-\mathrm{G}$ the particle size of AHPP/OVA nanoparticles was about $230 \mathrm{~nm}$, and particle size did not change after modification with PEI and $\mathrm{PPL}$. However, modification of nanoparticles with CS, resulted in particle sizes of approximately $330 \mathrm{~nm}$. AHPP/OVA showed a relatively negative surface charge $(-21.43 \mathrm{mV})$, while CS-AHPP/OVA, PEI-AHPP/OVA, and $\varepsilon$ PL-AHPP/OVA showed positive electrical charges $(+30 \mathrm{mV},+41.33 \mathrm{mV}$, and $+29.03 \mathrm{mV}$, respectively) due to surface cationic polymer modifications on the nanoparticle surfaces.

PEI-AHPP/OVA and $\varepsilon$ PL-AHPP/OVA nanoparticles showed surface morphologies and size distributions similar to those of AHPP/OVA, suggesting that surface cationic polymer modification had no influence on morphology, size, and dispersion of nanoparticles (Figure 1D, F, and G). After AHPP/OVA was modified by with CS, surface properties changed substantially, but completeness of the nanoparticles was maintained (Figure 1E).

\section{In vitro release and stability of nanoparticles}

As shown in Figure 2A, cumulative releases of OVA from AHPP/OVA showed three-phase kinetic phases, while the surfaces cationic polymer modified PLGA nanoparticles showed two kinetics phases. During the first 4 hrs, OVA was rapidly released from AHPP/OVA, CS-AHPP/OVA, PEI-AHPP/OVA, and \&PL-AHPP/OVA and the cumulative releases of OVA were $17.09 \%, 15.20 \%, 14.52 \%$, and $15.20 \%$, respectively. From 6 hrs to 35 days, OVA was released slowly from surfaces of cationic polymer modified PLGA nanoparticles. Cumulative release of OVA from CS-AHPP/OVA, PEI-AHPP/OVA, and $\varepsilon$ PL-AHPP /OVA on day 35 was $81.03 \%, 68.99 \%$, and $69.97 \%$, respectively. From $8 \mathrm{hrs}$ to 12 days, the cumulative releases of OVA from AHPP/OVA became slowly. However, from 12 days to 16 days, OVA release rate increased. After 17 days, the cumulative release of AHP and OVA slowed. Cumulative release results demonstrated that AHPP and surface cationic polymer modified PLGA nanoparticles effected slow release.

To observe the stability of AHP and OVA-loaded PLGA nanoparticles, PDI was determined. Aggregation of nanoparticles was observed over 28 days at $37^{\circ} \mathrm{C}$. The average PDI of nanoparticles initially increased during incubation. As shown in Figure 2B, the average PDI of AHPP/OVA nanoparticles within 14 days was less than 0.3 , and the PDI value reached 0.3 at day 21 , then rapidly increased. Average PDI values of the CS-AHPP/OVA within 21 days were less than 0.3 , then gradually increased to levels higher than 0.3 at day 28 . Average PDI of PEI-AHPP/OVA and \&PL-AHPP/OVA did not change 
A
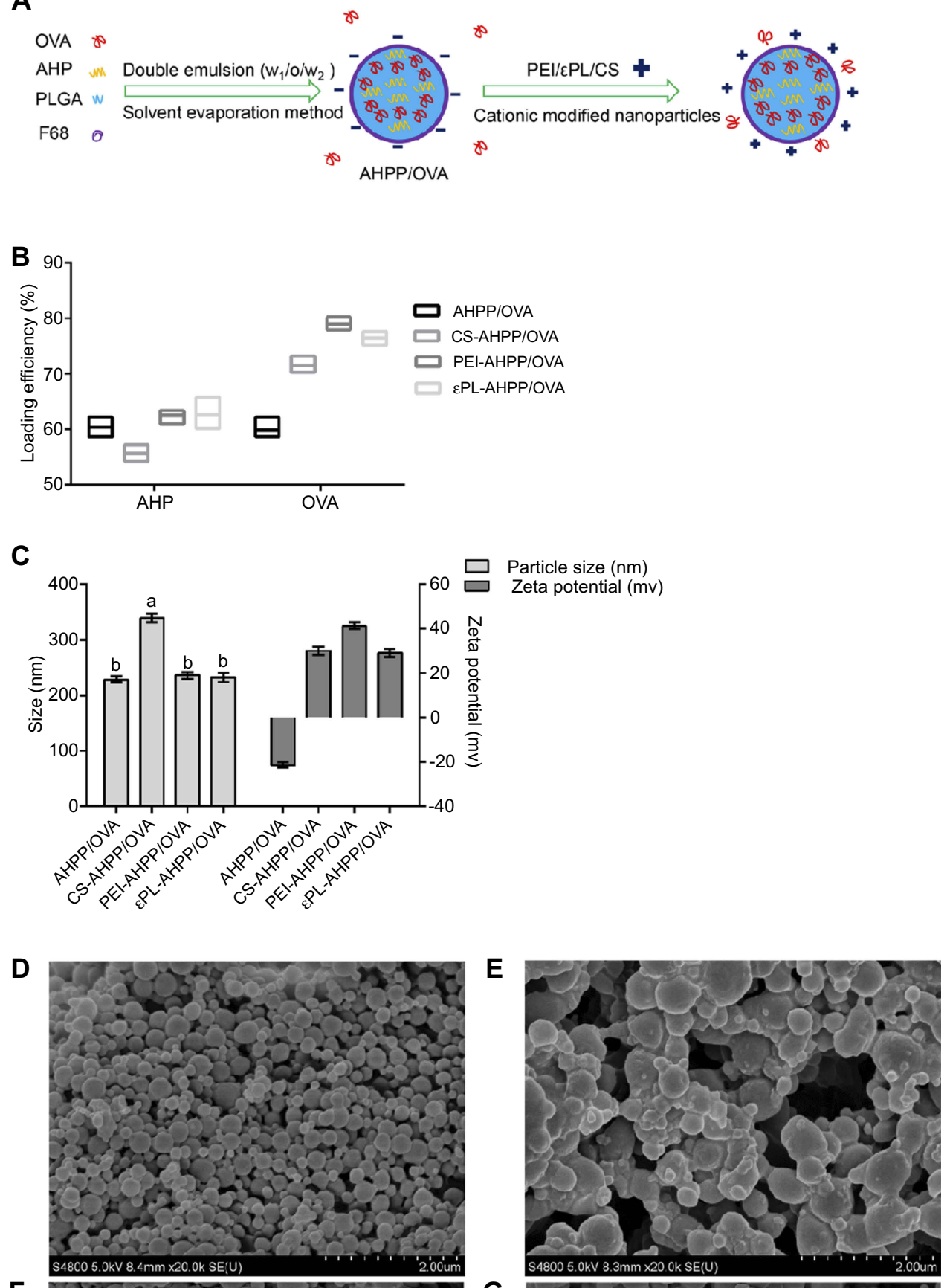

$\mathbf{F}$

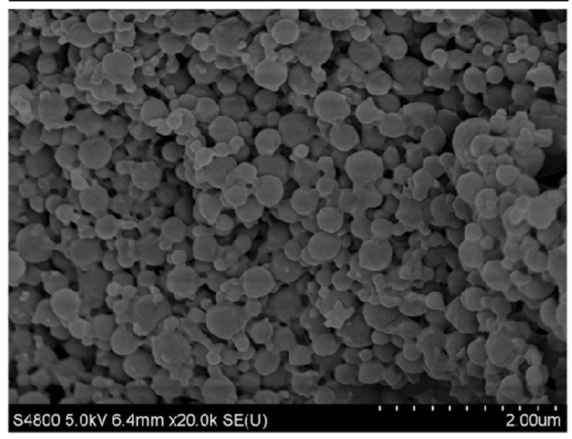

G

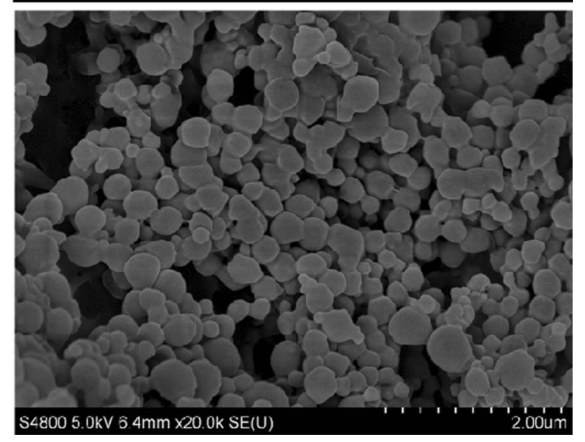

Figure I Characterization of AHPP/OVA and surface cationic polymer modified AHPP/OVA. (A) Schematic of OVA-loaded surface cationic polymer modified AHPP/OVA nanoparticles. (B) Loading efficiency of AHPP/OVA and surface cationic polymer modified AHPP/OVA nanoparticle dispersions stored at $37^{\circ} \mathrm{C}$. (C) Zeta-potential and particle size of AHPP/OVA, CS-AHPP/OVA, PEI-AHPP/OVA, and \&PL-AHPP/OVA. (D-G) SEM of AHPP/OVA, CS-AHPP/OVA, PEI-AHPP/OVA, and \&PL-AHPP/OVA. Results were expressed as means $\pm \operatorname{SEM}(n=3) .{ }^{a-b}$ Bars with different superscripts differed significantly $(P<0.05)$. 


\section{A}

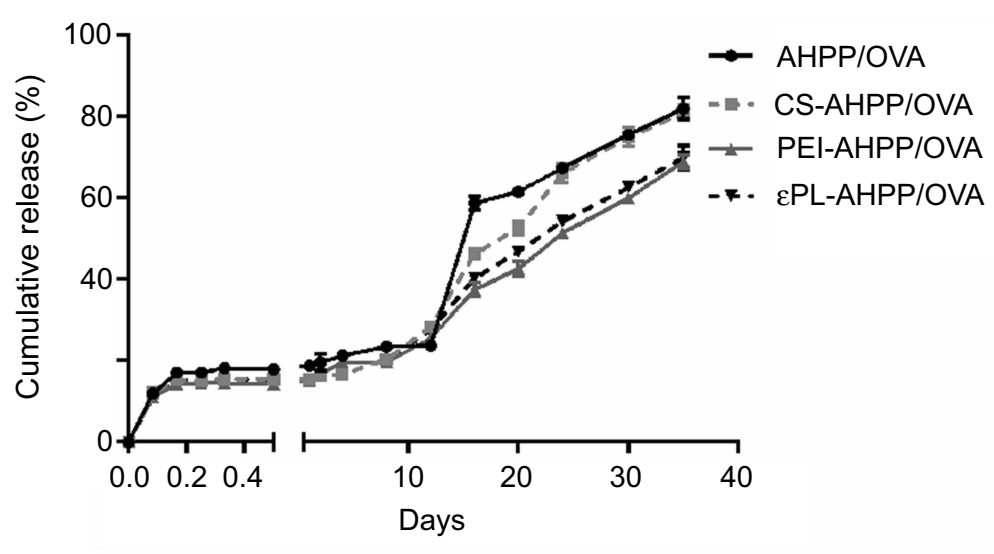

B
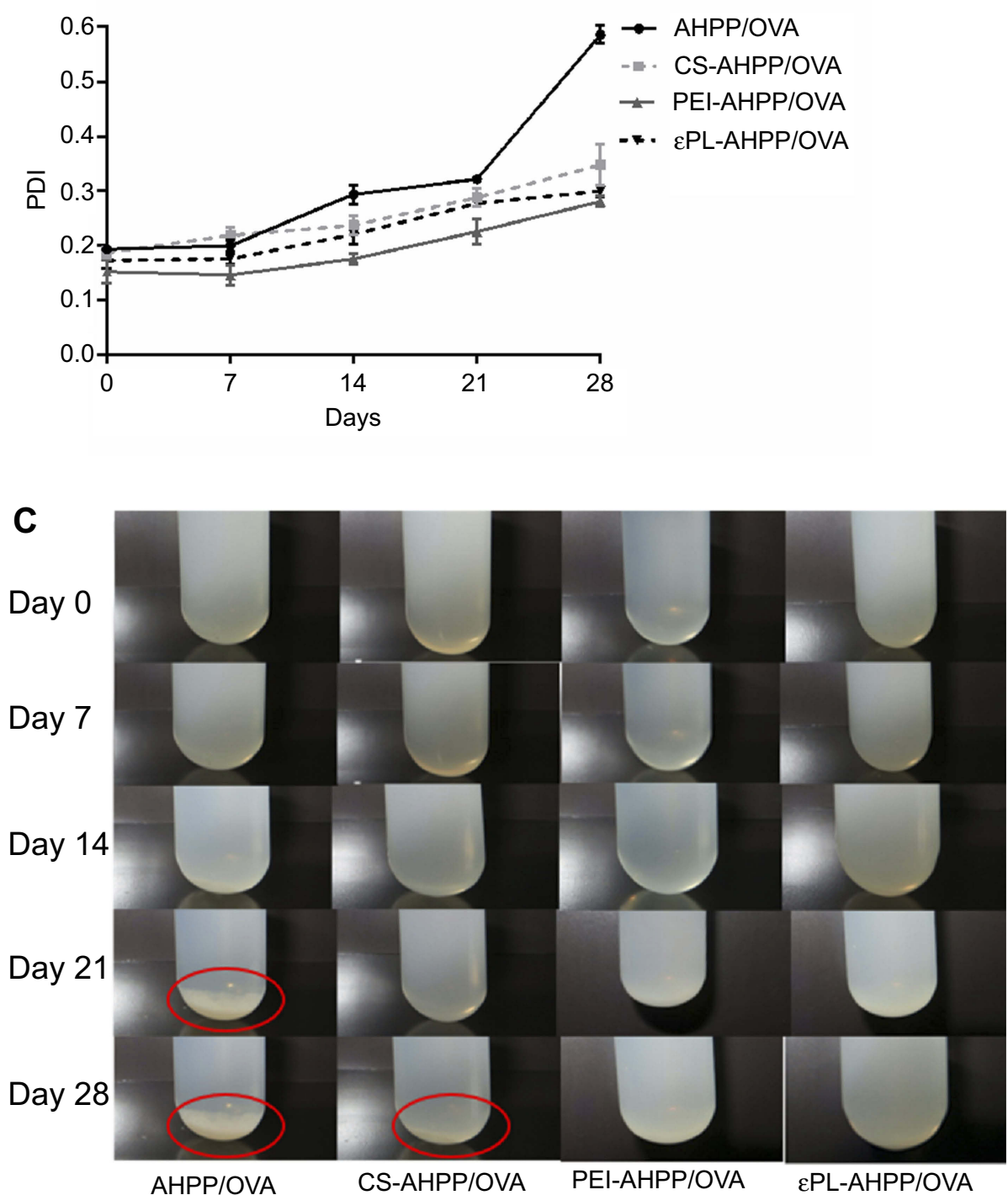

Figure 2 In vitro release and stability of AHPP/OVA and surface cationic polymer modified AHPP/OVA. (A) OVA release from the AHPP/OVA and surface cationic polymer modified AHPP/OVA incubated in deionized water $(\mathrm{pH}=7.0)$ for 35 days. (B) PDI of AHPP/OVA, CS-AHPP/OVA, PEI-AHPP/OVA, and $\varepsilon P L-A H P P / O V A$ dispersions stored at $37^{\circ} \mathrm{C}$. (C) Changes in the polymerization of AHPP/OVA, CS-AHPP/OVA, PEI-AHPP/OVA and \&PL-AHPP/OVA dispersions stored at $37^{\circ} \mathrm{C}$. Results were expressed as means $\pm \operatorname{SEM}(n=3)$. 
significantly changes (all less than 0.3 ), which suggested these types of nanoparticles exhibited a homogeneous particle size distribution over 28 days.

To observe the stability of the nanoparticles, nanoparticle solutions were placed in test tubes and sealed at $37^{\circ} \mathrm{C}$, and aggregation of nanoparticles was observed weekly. As shown in Figure $2 \mathrm{C}$, the AHPP/OVA group began to precipitate at day 21 , and continued to precipitate until day 28 , indicating that nanoparticles began to aggregate on the 21 st day. The CS-AHPP/OVA group began to precipitate at day 28. No precipitation occurred at day 28 in the PEIAHPP/OVA and $\varepsilon P L-A H P P / O V A$ groups.

\section{Splenocyte proliferation and OVA-specific $T$ cell activation}

Spleen lymphocyte proliferation was measured under following re-stimulation with OVA at day 21 after the second vaccination. As shown in Figure 3A, the proliferation index values of the AHP/OVA, AHPP/OVA, CS-AHPP/OVA, PEI-AHPP /OVA and $\varepsilon \mathrm{PL}-\mathrm{AHPP} / \mathrm{OVA}$ groups were significantly higher than those of the BP/OVA and OVA groups $(P<0.05)$, while no difference from the FCA/OVA group was observed $(P>0.05)$. Therefore, each of the AHP/OVA, AHPP/OVA, CS-AHPP /OVA, PEI-AHPP/OVA, and $\varepsilon P L-A H P P / O V A$ vaccine formulations can cause proliferation of spleen lymphocytes and lead to potent antigen-specific immune responses.

To further examine the effects of each formulation on $\mathrm{T}$ lymphocyte subpopulation ratio, antigen-specific $\mathrm{CD}^{+} /$ $\mathrm{CD}^{+} \mathrm{T}$ cells were evaluated by flow cytometry 21 days after the final immunization. As shown in Figure 3B, a significantly greater percentage of $\mathrm{CD}^{+} / \mathrm{CD}^{+} \mathrm{T}$ cells was observed in spleens of mice vaccinated with PEI-AHPP/OVA compared with all other groups $(P<0.05)$, while there were no significant differences among the between AHPP/OVA, CS-AHPP/OVA, $\varepsilon P L-A H P P / O V A$, and FCA/OVA groups $(P>0.05)$. T cell activation was elicited by PEI-AHPP/OVA, suggesting that this formulation induced a more effective immune response than the AHPP/OVA, CS-AHPP/OVA, \&PL-AHPP/OVA, and FCA/OVA formulations.

\section{Cytokine levels in serum}

Th1 cytokines (TNF- $\alpha$ and IFN- $\gamma$ ) and Th2 cytokines (IL-4 and IL-6) were measured in serum 35 days after final vaccination. As shown in Figure 4A and B, the PEI-AHPP/OVA formulation significantly increased expression of IL-4, IL-6, TNF- $\alpha$, and IFN- $\gamma$ compared to the AHP/OVA, AHPP/OVA, CS-AHPP/OVA, BP/OVA, and OVA groups $(P<0.05)$, which
A

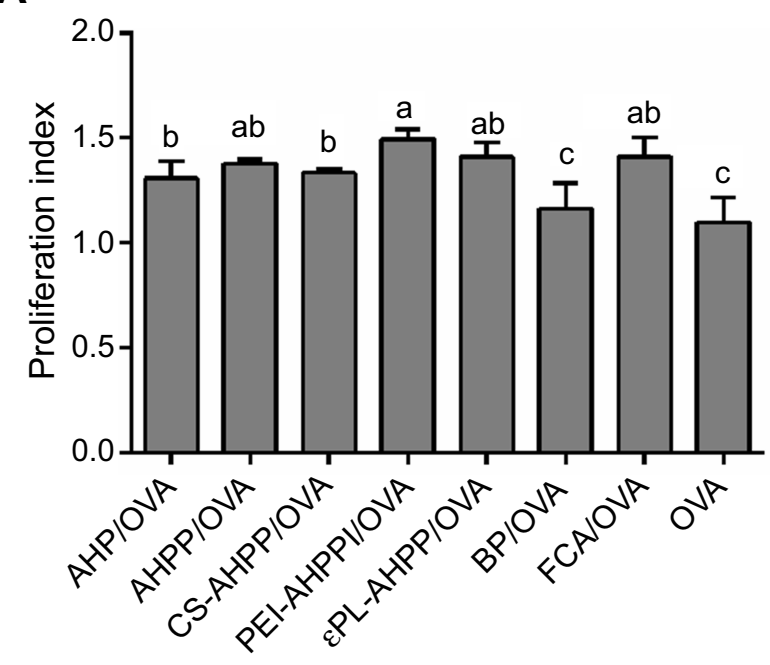

B

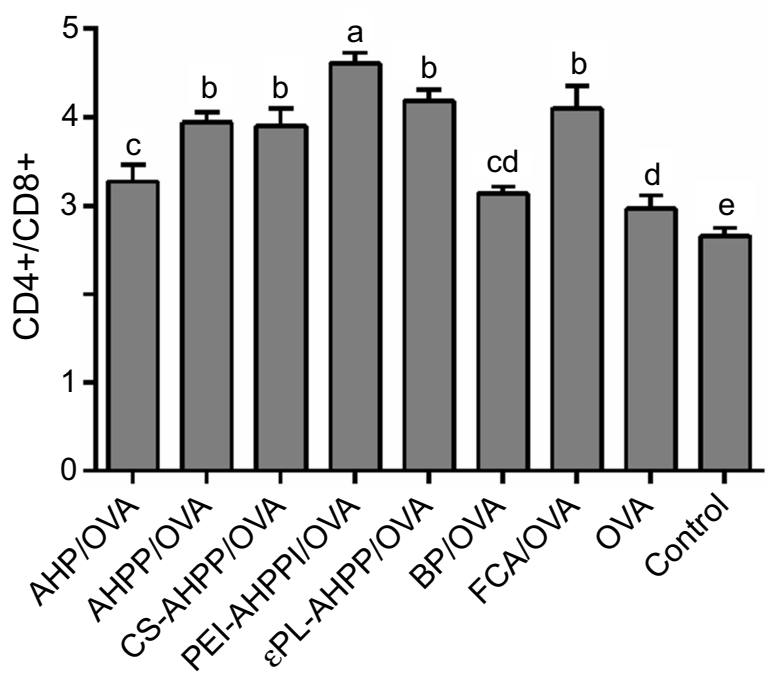

Figure 3 Antigen-specific $\mathrm{CD}^{+} / \mathrm{CD}^{+} \mathrm{T}$ cell activation. (A) Effects of drugs on splenic lymphocyte proliferation. (B) Ratio of $\mathrm{CD}^{+} \mathrm{CD}^{+}{ }^{+}$to $\mathrm{CD} 3^{+} \mathrm{CD} 8^{+}$splenocytes harvested from vaccinated mice re-stimulated with OVA. Mice $(n=4)$ were immunized using different vaccine formulations. ${ }^{a-e}$ Bars with different superscripts differed significantly $(P<0.05)$

indicated that PEI-AHPP/OVA enhanced both Th1-type and Th2-type immune responses. The $\varepsilon P L-A H P P / O V A$ formulation also induced showed high expression of IL-4, IL-6, TNF- $\alpha$, and IFN- $\gamma$, while no differenced from the AHPP/ OVA group were observed $(P>0.05)$. In addition, levels of TNF- $\alpha$ and IFN- $\gamma$ in the CS-AHPP/OVA group were lower than those in the AHPP/OVA group.

\section{Serum antibody responses}

To better understand the effects of various OVA formulations on antibody response, levels of OVA-specific serum 

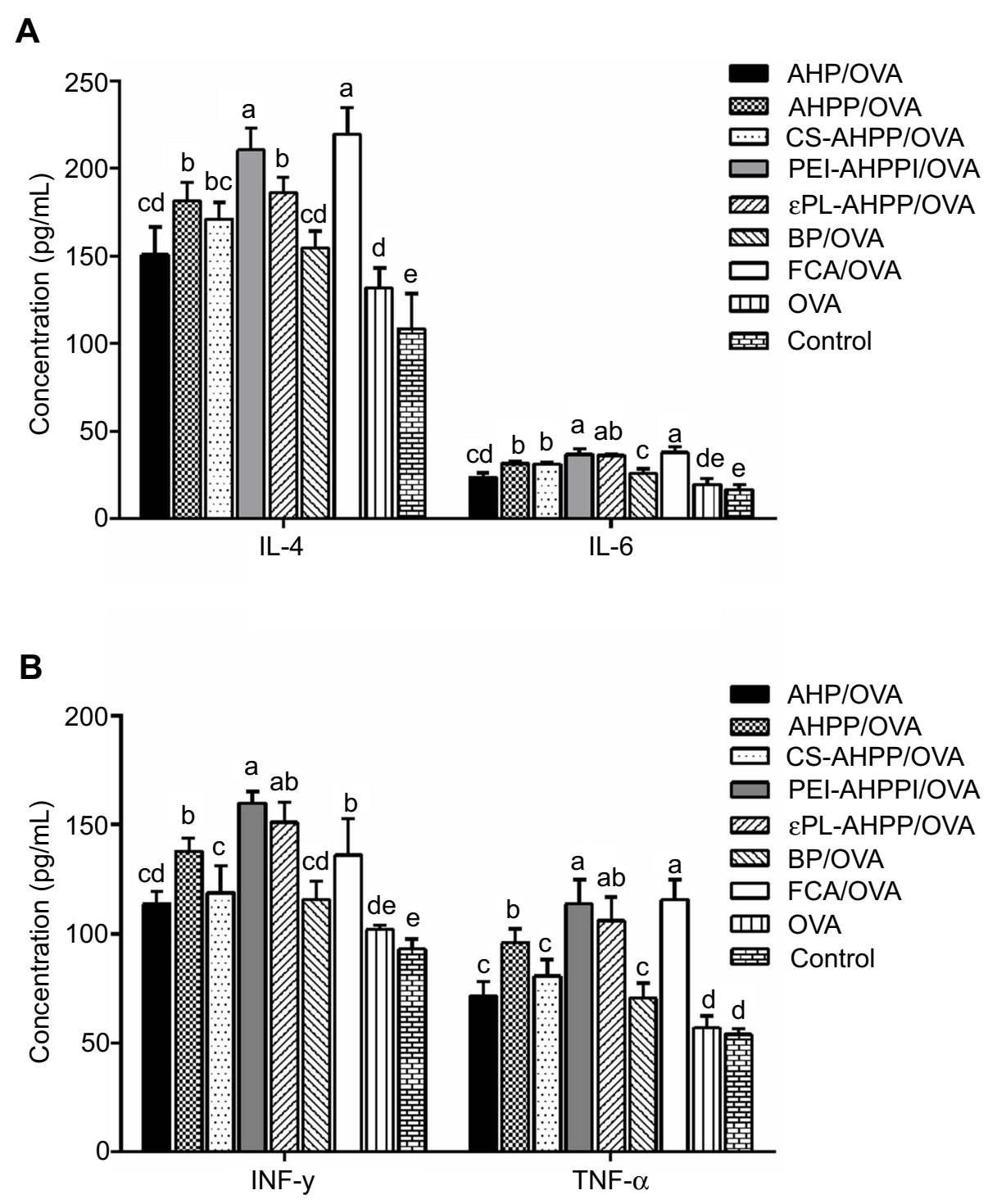

Figure 4 Cytokine secretion. (A) IL-4, IL-6, (B) IFN- $\gamma$, and TNF- $\alpha$ levels in serum 35 days after final immunization were measured by ELISA. Mice ( $\mathrm{n}=4$ ) were immunized using different vaccine formulations. ${ }^{-\mathrm{a}-\mathrm{e}}$ Bars with different superscripts differed significantly $(P<0.05)$.

IgG were determined using indirect ELISA analysis at days 7, 21, and 35 after the final immunization. As shown in Figure 5A, AHP/OVA induced significantly higher antigen-specific IgG levels than the BP/OVA and free OVA groups on day $7(P<0.05)$, but antibody levels on days 21 and 35 decreased significantly. PEI-AHPP /OVA induced significantly higher antigen-specific IgG levels than AHP/OVA, AHPP/OVA, CS-AHPP/OVA, BP/ OVA, FCA/OVA, and free OVA from days 7 to 35 after the final immunization $(P<0.05)$. High expression of $\operatorname{IgG}$ indicated that the PEI-AHPP/OVA formulation could induce a large and sustained humoral antibody response. The AHPP/OVA, CS-AHPP/OVA, \&PL-AHPP/OVA, and
FCA/OVA formulations also exhibited high IgG levels, but there was no significant difference between these groups.

As shown in Figure 5B, expression of IgG1 and IgG2a in response to PEI-AHPP/OVA was highest compared to all other groups, and $\varepsilon \mathrm{PL}-\mathrm{AHPP} / \mathrm{OVA}$ treatment resulted in expression of the second highest levels of IgG1 and IgG2. Immunization with the AHPP/OVA and CS-AHPP/OVA formulations resulted in nearly equal responses to the group injected with FCA at 35 days after final vaccination. In addition, PEI-AHPP /OVA induced the highest ratios of IgG2a/IgG1 compared to all other groups $(P<0.05)$. AHPP/OVA, $\varepsilon$ PL-AHPP/OVA, and FCA/OVA also induced higher ratios of IgG2a/IgG1 compared to AHP/OVA and BP/OVA $(P<0.05)$. However, the ratio of 


\section{A}

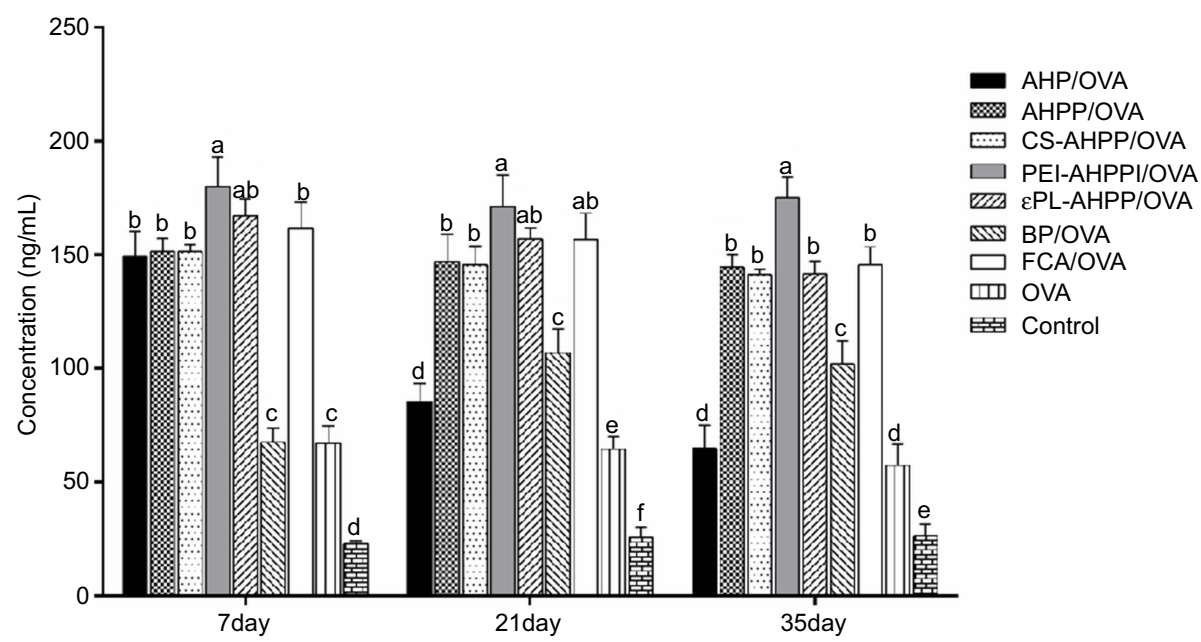

B

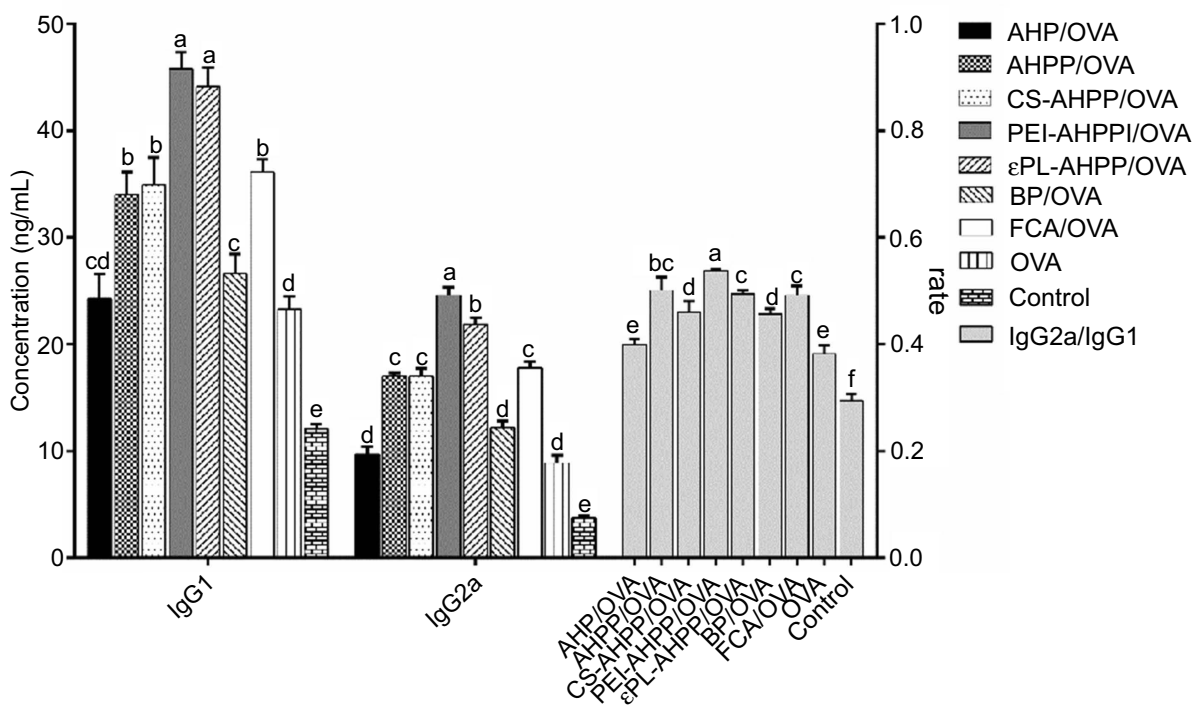

Figure 5 (A) OVA-specific lgG levels at the indicated time points. (B) Th2-associated isotype lgGI levels, ThI-associated isotype lgG2a levels, and ratio of IgG2a/lgGI at day 35 after final vaccination. Mice $(n=4)$ were immunized using different vaccine formulations. ${ }^{a-f}$ Bars with different superscripts differed significantly $(P<0.05)$.

IgG2a/IgG1 induced by the CS-AHPP group was not significantly different from that of the BP/OVA group $(P>0.05)$.

\section{H\&E staining of spleens}

The spleen is one of the most important immune organs in the body. As shown in Figure 6, mice vaccinated with AHPP/ OVA, CS-AHPP/OVA, PEI-AHPP/OVA, and $\varepsilon P L-A H P P$ /OVA formulations showed distinct changes in the spleen compared with the control group. Splenic corpuscles volumes of the surface cationic polymers modified AHPP/OVA group were larger than control and free OVA groups, and nearly similar to that of the FCA/OVA group, which suggested that modification of AHPP/OVA with cationic polymers (CS, PEI, and, $\varepsilon P L)$ enhanced the immune response.

\section{Discussion}

PLGA is one of the most widely synthesized biodegradable polymers, and is commonly used as a drug delivery system due to safety, biodegradability, stability in blood, and non-inflammatory properties. ${ }^{30,31}$ Antigen encapsulation into PLGA nanoparticles leads to slow antigen release from the nanoparticles, and provides long-term antigen 

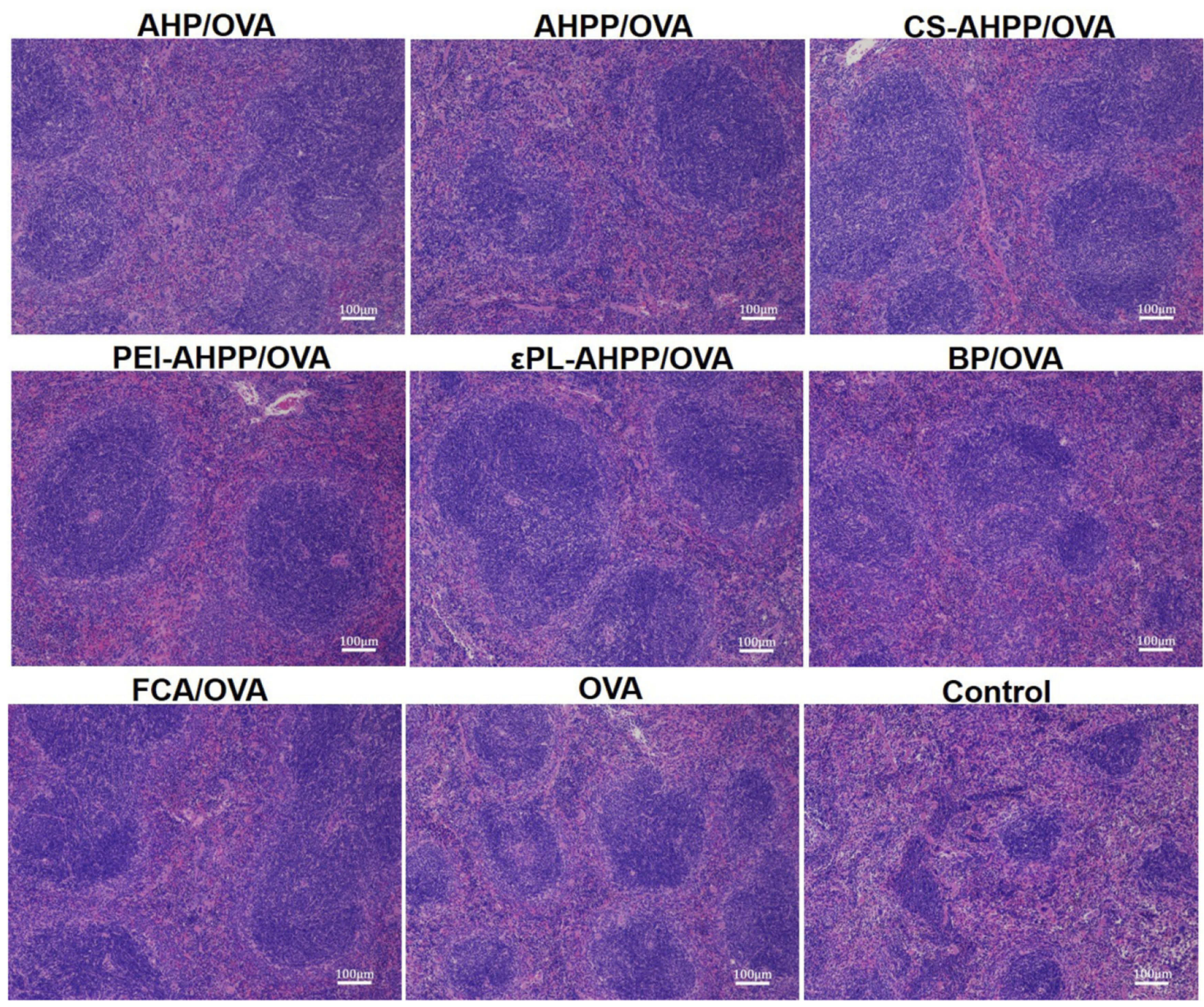

Figure 6 HE staining of spleens of immunized mice at day 35 after final vaccination. Scale bar represents $100 \mathrm{~nm}$.

persistence at the injection site after vaccination. ${ }^{32,33}$ However, a single antigen encapsulation strategy limits the antigen-loading efficiency and stability of PLGA nanoparticles. Many efforts have been made to increase the loading efficiency of nanoparticles, including altering particle size, shape, surface potential, and polymer types. ${ }^{34,35}$ Using these strategies, loading efficiency and stability of nanoparticles have been improved. In particular, coating of nanoparticles with cationic polymers that result in a positive surface charge has been considered to be an effective method. ${ }^{15,36,37}$

Positively charged nanoparticles allowed for efficient interaction with negatively charged cell membranes, which promotes phagocytosis of antigens by APCs and enhances the efficiency of antigen presentation. ${ }^{38,39}$ PLGA nanoparticles showed differential positive charging after modification with different cationic polymers (CS, $\varepsilon \mathrm{PL}$, and PEI). Antigen adsorption capacity was closely related to the surface charge of these PLGA nanoparticles. As shown in
Figure 1B, the loading efficiency of the OVA was greatly improved by surface cationic polymers modification, while the loading efficiency of AHP did not change. This may have been due to positive charging on the surface of the nanoparticles allowing for free OVA in solution to be adsorbed on the surface, thereby increasing loading efficiency of OVA (Figure 1A). Lower loading efficiency of AHP in the CS-AHPP/OVA group may have resulted from acidic conditions required to achieve CS surface modification, which may have damaged the PLGA nanoparticles, allowing AHP to dissociate from the nanoparticle.

Particle size and surface morphology changes of CSAHPP/OVA verified this effect. As shown in Figure 1C and E, particle size of CS-AHPP/OVA increased, reaching $330 \mathrm{~nm}$, and surface morphology also changed substantially. Larger particle size may have accelerated release of OVA and AHP from the nanoparticles. However, these effects should stop as acetic acid is evaporated, and a small amount of acetic acid in solution 
should not have a large impact on loading efficiency and completeness of the nanoparticles. Surface-modified $\varepsilon \mathrm{PL}-$ AHPP/OVA and PEI-AHPP/OVA showed size distributions and surface morphologies similar to those of AHPP/ OVA nanoparticles, suggesting that surface cationic polymers modification had no influence on the size and morphology of nanoparticles (Figure $1 \mathrm{C}-\mathrm{G}$ ).

Stability of nanoparticles was followed for 28 days at $37^{\circ} \mathrm{C}$. Change in PDI and precipitation of nanoparticles indicated that stability of AHPP/OVA nanoparticles improved after surface cationic polymers modification (Figure 2B and C). This may have resulted from a high positive charge on the surface of the nanoparticles. Furthermore, excellent stability of CS-AHPP/OVA, PEIAHPP/OVA and, عPL-AHPP/OVA could be explained by high surface charge and subsequent strong colloidal stability between particles. Nanoparticles size has been shown to influence the efficiency of lymph nodes (LNs) targeting and retention after injection. ${ }^{40}$ Nanoparticles with a particle size less than $80 \mathrm{~nm}$ can drain to $\mathrm{LNs}$ along with the interstitial flow. While nanoparticles larger than $100 \mathrm{~nm}$, are commonly taken up and carried to the LNs by migratory dendritic cells. ${ }^{41,42}$ AHPP/OVA and surface cationic polymer modified PLGA nanoparticles have particle sizes larger than $200 \mathrm{~nm}$, and exhibited good stability controlled the release of OVA. Therefore, AHPP/OVA and surface cationic polymer modified PLGA nanoparticle formulations could provide long-lasting antigen persistence at the injection site after immunization. Nanoparticles resident in LNs can also be taken up by dendritic cells and enhanced the induction $\mathrm{CD}^{+}$or $\mathrm{CD}^{+} \mathrm{T}$ cells in the body.

Lymphocyte proliferation is an indicator of immunestimulation, and reflects the level of cellular immune response. $^{43,44}$ Our results demonstrated that the AHP/ OVA, AHPP/OVA, CS-AHPP/OVA, PEI-AHPP/OVA, and $\varepsilon$ PL-AHPP/OVA formulations induced strong cellular immune responses. In the present study, high $\mathrm{CD}^{+} / \mathrm{CD}^{+}$ lymphocyte ratio was considered a key immunological event has been observed in individuals with increased immune capacity. ${ }^{45,46}$ As shown in Figure 3B, the highest $\mathrm{CD}^{+} / \mathrm{CD}^{+}$lymphocyte ratios were observed in spleens in the PEI-AHPP/OVA group, This ratio was, significantly higher than those in the AHPP/OVA, and FCA/OVA groups. AHPP/OVA, CS-AHPP/OVA, and $\varepsilon P L-A H P P$ /OVA induced significantly higher $\mathrm{CD}^{+} / \mathrm{CD}^{+}$lymphocyte ratios than that in the OVA group, but did not induce a significantly different ratio than the FCA/OVA group. The above results indicated that AHPP/OVA enhanced
T cell immunity, and this effect was significantly enhanced by PEI modification.

Th1 cytokines (TNF- $\alpha$, IFN- $\gamma$ ) reflect the cellular immune response, and Th2 cytokines (IL-4 and IL-6) mediate the humoral immune response. ${ }^{47,48}$ As shown in Figure $4 \mathrm{~A}$ and $\mathrm{B}$, mice immunized with the PEI-AHPP/OVA and $\varepsilon$ PL-AHPP /OVA formulations showed increased numbers number of T cells and levels of TNF- $\alpha$, IFN- $\gamma$, IL-4, and IL-6 compared to levels of these cytokines induced by the AHP/OVA and AHPP/OVA formulations. These results indicated that the PEI-AHPP/OVA and $\varepsilon P L-A H P P / O V A$ vaccine formulations could enhance both Th1-type and Th2-type immune responses. In addition, PEI-AHPP/OVA induced significantly higher IFN- $\gamma$ production compared to that of the FCA/OVA group $(P<0.05)$, and levels of TNF- $\alpha$ and IFN- $\gamma$ induced by PEI-AHPP/OVA and $\varepsilon P L-A H P P / O V A$ were not significantly different than those induced by FCA $(P>0.05)$. The AHPP/ OVA formulation also induced high IFN- $\gamma$ expression equivalent to that observed in response to FCA treatment $(P>0.05)$. FCA is known to promote a robust antibody and Th1-type response. ${ }^{49,50}$ As such, these data suggested that the AHPP/ OVA, PEI-AHPP/OVA, and عPL-AHPP/OVA formulations mainly induced a stronger Th1 immune response. TNF- $\alpha$ and IFN- $\gamma$ levels induced by CS-AHPP/OVA formulation were lower than those induced by AHPP/OVA, which indicated that CS surface modification reduced AHPP/OVAinduced Th1 immune response.

As shown in Figure 5A, the AHPP/OVA, CS-AHPP /OVA, PEI-AHPP/OVA, and $\varepsilon P L-A H P P / O V A$ formulations significantly enhanced production of $\mathrm{IgG}$ compared with free OVA $(P<0.05)$, among which PEI-AHPP/OVA induced the highest IgG secretion. The other three formulations induced a similar response to that of the FCA/OVA formulation at days 7, 21, and 35 after the final immunization. These results indicated that PEI modification is an effective way strategy induce high $\lg$ G production. IgG1 antibody production is characteristic of a Th2-polarized immune response, while $\operatorname{IgG} 2$ a antibody production is characteristic of a Th1-polarized immune response. The ratio of $\operatorname{IgG} 2 \mathrm{a} / \mathrm{IgG} 1$ is indicative of a Th1-biased immune response. $^{51,52}$ Our results showed that the PEI-AHPP/OVA formulation induced the greatest Th1-associated IgG2a response and Th2-associated IgG1 responses. The AHPP/ OVA, CS-AHPP/OVA, and $\varepsilon P L-A H P P / O V A$ formulations induced large $\mathrm{IgG} 2 \mathrm{a}$ and $\mathrm{IgG} 1$ responses. FCA is known to induce strong Th-1 polarized humoral immune responses. The IgG2a/IgG1 ratio resulting from PEI-AHPP/OVA immunization was significantly higher than that of FCA/ 
OVA immunization, while AHPP/OVA and $\varepsilon P L-A H P P$ /OVA administration resulted in $\mathrm{IgG} 2 \mathrm{a} / \mathrm{IgG} 1$ ratios nearly equal to that of the FCA/OVA group (Figure 5B), further demonstrating that AHPP/OVA, PEI-AHPP/OVA, and \&PL-AHPP/OVA generated a strong Th1-biased immune response, among which $\mathrm{PEI}-\mathrm{AHPP} / \mathrm{OVA}$ immunization induced the strongest Th1 polarized response.

\section{Conclusion}

In this study, high antigen-loading efficiency and good stability of the nanoparticles can be achieved by surface cationic polymers (CS, PEI, and $\varepsilon P L$ ) modification. Surface cationic polymers modification does not damage the structural integrity of the AHPP/OVA nanoparticles. AHPP/OVA and three surface cationic polymers synthesized from modified AHPP/OVA nanoparticles significantly enhanced lymphocyte proliferation and improved the ratio of $\mathrm{CD} 4+/ \mathrm{CD} 8+\mathrm{T}$ cells in immunized mice. In all treatment groups, the PEI-AHPP/OVA formulation induced the highest cytokines secretion of TNF- $\alpha$, IFN- $\gamma$, IL-4, and IL-6 and the levels of antibodies (IgG) and antibody subtypes (IgG1 and IgG2a). In summary, the PEI-AHPP/OVA formulation could potentially serve as a novel and effective vaccine adjuvant to induce strong and long-term immune responses.

\section{Abbreviation list}

AHP, Alhagi honey polysaccharides; PLGA, poly(lactic-co -glycolic acid); F68, Pluronic F68; CS, chitosan; PEI, polyethyleneimine; $\varepsilon P L, \varepsilon$-Poly-L-lysine; MW, molecular weight; EE, encapsulation efficiency; PDI, poly dispersity index; CD3e, anti-Mouse-CD3e-FITC; CD4, anti-MouseCD4-APC; CD8a, anti-Mouse-CD8a-FITC antibodies; FCA, Freund's Adjuvant Complete; OVA, ovalbumin; SEM, scanning electron microscope; PBS, phosphate buffer solution; MTT, 3-(4,5-dimethylthiazol-2-yl)-2,5-diphenyltetrazolium bromide; DMSO, dimethyl sulfoxide; APC, antigen-presenting cell; ELISA, enzyme-linked immunosorbent assay.

\section{Acknowledgments}

This project was supported by the National Natural Science Foundation of China (Grant nos. 31872509, 31672596), the Fundamental Research Funds for the Central Universities (Grant no. KYZ201844) and the Priority Academic Program Development of Jiangsu Higher Education Institutions (PAPD). We are grateful to all of the other staff members at the Institute of Traditional
Chinese Veterinary Medicine of Nanjing Agricultural University for their assistance in this study.

\section{Disclosure}

No potential conflicts of interest were reported by the authors in this work.

\section{References}

1. Huang W, Zhang C. Tuning the size of poly(lactic-co-glycolic acid) (PLGA) nanoparticles fabricated by nanoprecipitation. Biotechnol $J$. 2017;13(1):1-19. doi:201700203

2. Ray S, Ghosh RS, Mandal S. Development of bicalutamide-loaded PLGA nanoparticles: preparation, characterization and in-vitro evaluation for the treatment of prostate cancer. Artif Cells Nanomed Biotechnol. 2017;33(5):944-954. doi:10.1080/21691401.2016.1196457

3. Mir M, Ahmed N, Rehman AU. Recent applications of PLGA based nanostructures in drug delivery. Colloids Surf B Biointerfaces. 2017;159:217-231. doi:10.1016/j.colsurfb.2017.07.038

4. Cruz LJ, Tacken PJ, Eich C, Rueda F, Torensma R, Figdor CG. Controlled release of antigen and toll-like receptor ligands from PLGA nanoparticles enhances immunogenicity. Nanomedicine. 2017;12(5):491-510. doi:10.2217/nnm-2016-0295

5. Vivek R, Thangam R, Kumar SR, et al. HER2 targeted breast cancer therapy with switchable "Off/On" multifunctional "Smart" magnetic polymer core-shell nanocomposites. ACS Appl Mater Interfaces. 2016;8(3):2262-2279. doi:10.1021/acsami.5b11103

6. Liu Q, Chen X, Jia J, et al. pH-responsive poly(D,L-lactic-co-glycolic acid) nanoparticles with rapid antigen release behavior promote immune response. ACS Nano. 2015;9(5):4925-4938. doi:10.1021/ nn5066793

7. Zhou N, Hu K, Guo Z, et al. Thermo-sensitive PLGA-PEG-PLGA tri-block copolymer hydrogel as three-dimensional cell culture matrix for ovarian cancer cells. J Nanosci Nanotechnol. 2018;18 (8):5252-5255. doi:10.1166/jnn.2018.15372

8. Apostólico JS, Lunardelli VA, Coirada FC, Boscardin SB, Rosa DS. Adjuvants: classification, modus operandi, and licensing. J Immunol Res. 2016;2016. doi:1459394.

9. Hafner AM, Corthésy B, Textor M, Merkle HP. Surface-assembled poly(I:C) on PEGylated PLGA microspheres as vaccine adjuvant: APC activation and bystander cell stimulation. Int $J$ Pharm. 2016;514(1):176-188. doi:10.1016/j.ijpharm.2016.07.042

10. Hamdy S, Elamanchili P, Alshamsan A, Molavi O, Satou T, Samuel J. Enhanced antigen-specific primary CD4+ and CD8+ responses by codelivery of ovalbumin and toll-like receptor ligand monophosphoryl lipid A in poly(D,L-lactic-co-glycolic acid) nanoparticles. J Biomed Mater Res A. 2010;81(3):652-662. doi:10.1002/jbm.a.31019

11. Luo WH, Yang YW. Activation of antigen-specific CD8(+) T cells by POLY-DL-Lactide/Glycolide (PLGA) nanoparticle-primed Gr-1 (high) cells. Pharm Res. 2016;33(4):942-955. doi:10.1007/s11095015-1840-X

12. Chen X, Liu Y, Wang L, et al. Enhanced humoral and cell-mediated immune responses generated by cationic polymer-coated PLA microspheres with adsorbed HBsAg. Mol Pharm. 2014;11(6):1772-1784. doi:10.1021/mp400597z

13. Zhi ZL, Haynie DT. High-capacity functional protein encapsulation in nanoengineered polypeptide microcapsules. Chem Comm. 2005;37:147-149. doi:10.1039/b511353a

14. Fleur A, Denys B, Josette P, et al. Dendritic cells loaded with HIV-1 p24 proteins adsorbed on surfactant-free anionic PLA nanoparticles induce enhanced cellular immune responses against HIV-1 after vaccination. Vaccine. 2009;27(38):5284-5291. doi:10.1016/j. vaccine.2009.05.028 
15. Liu L, Cao F, Liu X, et al. Hyaluronic acid-modified cationic lipid-PLGA hybrid nanoparticles as a nanovaccine induce robust humoral and cellular immune responses. ACS Appl Mater Interfaces. 2016;8(19):11969-11979. doi:10.1021/acsami.6b01135

16. Song YL, Jung E, Park JH, et al. Transient aggregation of chitosan-modified poly(d, 1 -lactic-co-glycolic) acid nanoparticles in the blood stream and improved lung targeting efficiency. $J$ Colloid Interface Sci. 2016;480:102-108. doi:10.1016/j.jcis.2016.07.006

17. Yu K, Zhao J, Zhang Z, et al. Enhanced delivery of Paclitaxel using electrostatically-conjugated Herceptin-bearing PEI/PLGA nanoparticles against HER-positive breast cancer cells. Int J Pharm. 2016;497 (1):78-87. doi:10.1016/j.ijpharm.2015.11.033

18. Deshpande S, Venugopal E, Ramagiri S, Bellare JR, Kumaraswamy G, Singh N. Enhancing cubosome functionality by coating with a single layer of poly-e-lysine. ACS Appl Mater Interfaces. 2014;6(19):17126-17133. doi:10.1021/am5047872

19. Lim HJ, Kim JK, Park JS. Complexation of apoptotic genes with polyethyleneimine (PEI)-Coated Poly-(DL)-Lactic-Co-Glycolic acid nanoparticles for cancer cell apoptosis. J Biomed Nanotechnol. 2015;11(2):211-225.

20. Ping Z, Tong A, Chuan Z, et al. Lactosylated PLGA nanoparticles containing $\epsilon$-polylysine for the sustained release and liver-targeted delivery of the negatively charged proteins. Int J Pharm. 2015;478 (2):633-643. doi:10.1016/j.ijpharm.2014.12.017

21. Takeuchi I, Takeshita T, Suzuki T, Makino K. Iontophoretic transdermal delivery using chitosan-coated PLGA nanoparticles for positively charged drugs. Colloids Surf B Biointerfaces. 2017;160 (1):520-526. doi:10.1016/j.colsurfb.2017.10.011

22. Chen HL, Li DF, Chang BY, Gong LM, Dai JG, Yi GF. Effects of Chinese herbal polysaccharides on the immunity and growth performance of young broilers. Poult Sci. 2003;82(3):364-370. doi:10.1093/ps/82.3.364

23. Jiang $\mathrm{MH}$, Zhu L, Jiang JG. Immunoregulatory actions of polysaccharides from Chinese herbal medicine. Expert Opin Ther Targets. 2010;14(2):1367-1402. doi:10.1517/14728222.2010.531010

24. Srivastava B, Sharma H, Dey YN, Wanjari MM, Jadhav AD. Alhagi pseudalhagi: a review of its phyto-chemistry, pharmacology, folklore claims and ayurvedic studies. Int J Her Med. 2014;2 (2):1367-1402.

25. Li G, Xiang Y, Zhao J, Chang J. Saccharum Alhagi polysaccharide-1 and -2 promote the immunocompetence of RAW264.7 macrophages in vitro. Exp Ther Med. 2018;15(4):3556-3562. doi:10.3892/etm.2018.5818

26. Gulzar M, Muhammad Ajaz H, Farooq A, Muhammad A, AnwarulHassan G. Alhagi: a plant genus rich in bioactives for pharmaceuticals Phytother Res. 2015;29(1):1-13. doi:10.1002/ptr.5222

27. Li-Jun J, Jun-Min C, Mourboul A, Gai-Ru L, Jia-Wei H. Isolation, purification, and structural elucidation of polysaccharides from Alhagi-honey. $J$ Asian Nat Prod Res. 2014;16(7):783-789. doi:10.1080/10286020.2014.898633

28. Gu P, Xu S, Zhou S, et al. Optimization of angelica sinensis polysaccharide-loaded poly (lactic-co-glycolicacid) nanoparticles by RSM and its immunological activity in vitro. Int J Biol Macromol. 2017;107(A):222-229. doi:10.1016/j.ijbiomac.2017.08.176

29. Ye L, Zhang J, Ye X, et al. Structural elucidation of the polysaccharide moiety of a glycopeptide (GLPCW-II) from Ganoderma lucidum fruiting bodies. Carbohydr Res. 2008;343(4):746-752. doi:10.1016/j. carres.2007.12.004

30. Danhier F, Ansorena E, Silva JM, Coco R, Le BA, Préat V. PLGA-based nanoparticles: an overview of biomedical applications. J Control Release. 2012;161(2):505-522. doi:10.1016/j.jconrel.2012.01.043

31. Panyam J, Labhasetwar V. Biodegradable nanoparticles for drug and gene delivery to cells and tissue. Adv Drug Deliv Rev. 2002;64 (2012):61-71. doi:10.1016/j.addr.2012.09.023
32. Prasad S, Cody V, Saucier-Sawyer JK, et al. Optimization of stability, encapsulation, release, and cross-priming of tumor antigen-containing PLGA nanoparticles. Pharm Res. 2012;29(9):2565-2577. doi:10.1007/ s11095-012-0787-4

33. Furtmann B, Tang J, Kramer S, et al. Electrospray synthesis of PLGA nanoparticles encapsulating peptides to enhance proliferation of antigen-specific $\mathrm{CD} 8(+) \quad \mathrm{T}$ cells. $J$ Pharm Sci. 2017;106 (11):3316-3327. doi:10.1016/j.xphs.2017.06.013

34. Manmohan S, Jina K, Mildred U, Padma M, James C, O`Hagan DT. Polylactide-co-glycolide microparticles with surface adsorbed antigens as vaccine delivery systems. Curr Drug Deliv. 2006;3 (1):115-120. doi:10.2174/156720106775197565

35. Bee SL, Hamid ZAA, Mariatti M, et al. Approaches to improve therapeutic efficacy of biodegradable PLA/PLGA microspheres: a review. Poly Rev. 2018;58(3):1-42. doi:10.1080/15583724.2018.1437547

36. Liu L, Ma P, Wang H, et al. Immune responses to vaccines delivered by encapsulation into and/or adsorption onto cationic lipid-PLGA hybrid nanoparticles. J Control Release. 2016;225(10):230-239. doi:10.1016/j.jconrel.2016.01.050

37. Kim S, Shi Y, Ji YK, Park K, Cheng JX. Overcoming the barriers in micellar drug delivery: loading efficiency, stability, and micelle-cell interaction. Expert Opin Drug Deliv. 2010;7(1):49-62. doi:10.1517/ 17425240903380446

38. Lars T, Diederichs JE, Regina R, Merkle HP, Elke W. Competitive adsorption of serum proteins at microparticles affects phagocytosis by dendritic cells. Biomaterials. 2003;24(8):1409-1418.

39. Nguyun DN, Green JJ, Chan JM, Longer R, Anderson DG. Polymeric materials for gene delivery and DNA vaccination. $A d v$ Mater. 2010;21(8):847-867.

40. Pal I, Ramsey JD. The role of the lymphatic system in vaccine trafficking and immune response. Adv Drug Deliv Rev. 2011;63 (10):909-922. doi:10.1016/j.addr.2011.05.018

41. Liu H, Irvine DJ. Guiding principles in the design of molecular bioconjugates for vaccine applications. Bioconjug Chem. 2015;26 (5):791-801. doi:10.1021/acs.bioconjchem.5b00103

42. An M, Li M, Xi J, Liu H. Silica nanoparticle as a lymph node targeting platform for vaccine delivery. ACS Appl Mater Interfaces. 2017;9(28):23466-23475. doi:10.1021/acsami.7b06024

43. Tan L, Zhang Y, Qiao C, et al. NDV entry into dendritic cells through macropinocytosis and suppression of $\mathrm{T}$ lymphocyte proliferation. Virology. 2018;518(2):126-135. doi:10.1016/j.virol.2018.02.011

44. Zhu ZY, Zhang JY, Liu F, Chen L, Chen LJ, Tang Y. Characterization and lymphocyte proliferation activity of an oligosaccharide degraded from Astragalus polysaccharide. Medchemcomm. 2017;8 (7):1521-1530. doi:10.1039/c7md00148g

45. Lee JA, Jung BG, Kim TH, et al. Poly d, 1 -lactide-co-glycolide (PLGA) nanoparticle-encapsulated honeybee (Apis melifera) venom promotes clearance of Salmonella enterica serovar Typhimurium infection in experimentally challenged pigs through the up-regulation of $\mathrm{T}$ helper type 1 speci. Vet Immunol Immunopathol. 2014;161(3-4):193-204. doi:10.1016/j.vetimm.2014.08.010

46. Meihong X, Ming Z, Ruiyue Y, Zhaofeng Z, Yong L, Junbo W. Effect of dietary nucleotides on immune function in $\mathrm{Balb} / \mathrm{C}$ mice. Int Immunopharmacol. 2013;17(1):50-56. doi:10.1016/j.intimp. 2013.04.032

47. Cox JH, Ferrari G, Janetzki S. Measurement of cytokine release at the single cell level using the ELISPOT assay. Methods. 2006;38 (4):274-282. doi:10.1016/j.ymeth.2005.11.006

48. Feng H, Du X, Liu J, Han X, Cao X, Zeng X. Novel polysaccharide from Radix Cyathulae officinalis Kuan can improve immune response to ovalbumin in mice. Int $J$ Biol Macromol. 2014;65 (2014):121-128. doi:10.1016/j.ijbiomac.2014.01.017 
49. Liu Z, Xing J, Zheng S, et al. Ganoderma lucidum polysaccharides encapsulated in liposome as an adjuvant to promote Th1-bias immune response. Carbohydr Polym. 2016;142(2016):141-148. doi:10.1016/j.carbpol.2016.01.021

50. Xing J, Liu Z, Huang Y, et al. Lentinan-modified carbon nanotubes as an antigen delivery system modulate immune response in vitro and in vivo. ACS Appl Mater Interfaces. 2016;8(30):19276-19283. doi:10.1021/acsami.6b04591
51. Wang D, Zhao Y, Sun Y, Yang X. Protective effects of Ziyang tea polysaccharides on CCl4-induced oxidative liver damage in mice. Food Chem. 2014;143(2014):371-378. doi:10.1016/j.foodchem.2013.08.005

52. Fotouhi F, Shaffifar M, Farahmand B, et al. Adjuvant use of the NKT cell agonist alpha-galactosylceramide leads to enhancement of M2-based DNA vaccine immunogenicity and protective immunity against influenza A virus. Arch Virol. 2017;162(5):1251-1260. doi:10.1007/s00705-017-3230-7

\section{Publish your work in this journal}

The International Journal of Nanomedicine is an international, peerreviewed journal focusing on the application of nanotechnology in diagnostics, therapeutics, and drug delivery systems throughout the biomedical field. This journal is indexed on PubMed Central, MedLine, CAS, SciSearch ${ }^{\circledR}$, Current Contents ${ }^{\circledR} /$ Clinical Medicine,
Journal Citation Reports/Science Edition, EMBase, Scopus and the Elsevier Bibliographic databases. The manuscript management system is completely online and includes a very quick and fair peer-review system, which is all easy to use. Visit http://www.dovepress.com/ testimonials.php to read real quotes from published authors. 